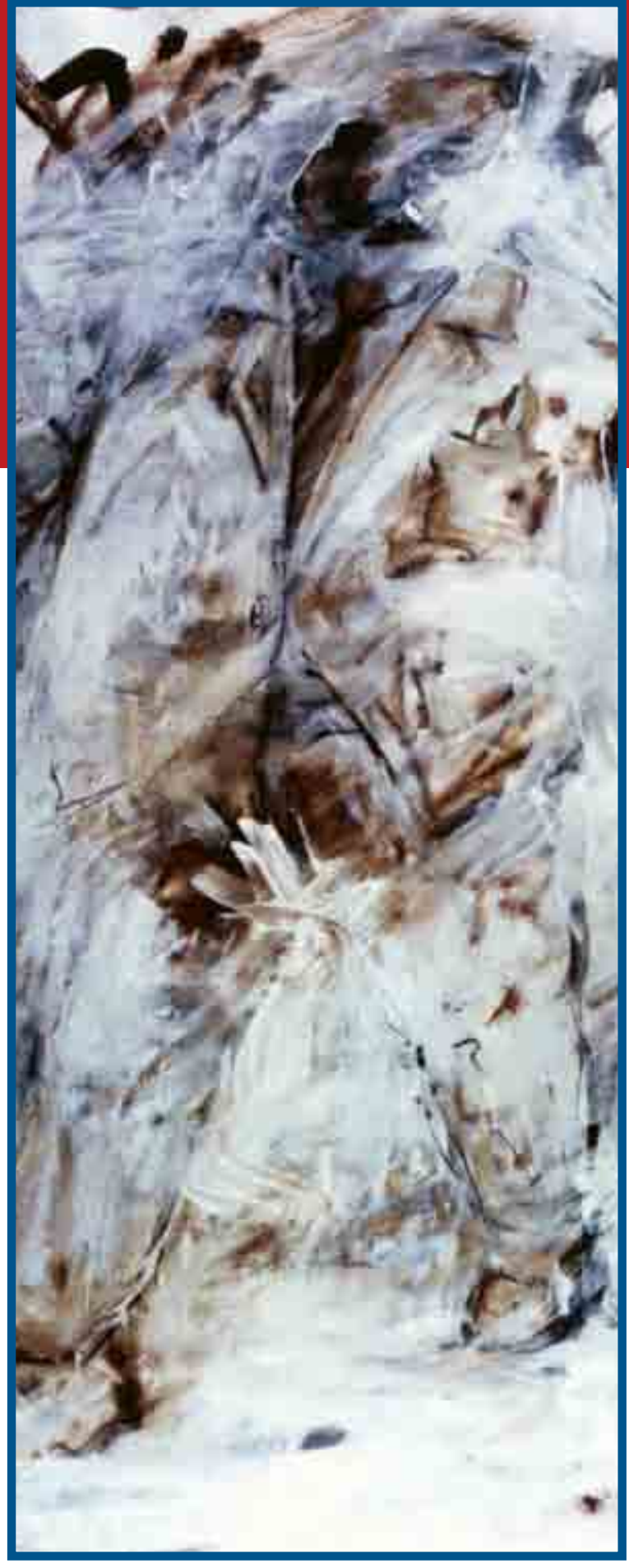

Don dinero

Mixta sobre papel, 1996

\section{Religión y Universidad}

Ante los alcances y las perspectivas de progresos de la ciencia y de la técnica, muchos, postulando que la religión está relacionada con fenómenos o aspectos de la vida y del mundo transitoriamente inexplicado, profetizaron que ella, paulatinamente, desplazaría sus fronteras a medida de los avances de la racionalidad científica, hasta desaparecer del horizonte del ser humano. La corriente filosófica del iluminismo había abierto ese camino $\mathrm{y}$, entusiasmados por la Revolución industrial de los siglos XVIII-IXX en Europa, algunos anunciaron el declinar de la religión. El filosofo Karl Marx y sus seguidores difundieron bastante esa opinión, presentando la religión no solo como una realidad prelógica, sino también como un opio, una esclavitud para el ser humano.

¿Quién puede decir que desde entonces, la ciencia y la técnica no progresaron? Sin embargo, lo que la actualidad nos lleva a observar no es necesariamente la tendencia hacia la desaparición del sentimiento religioso en las personas, las esferas geográficas, los exponentes y los escenarios de tales progresos. A este respec-

Doctor en derecho canónico e internacional. Miembro del servicio diplomático de la Santa Sede desde 1995. Actualmente es consejero de Nunciatura de la república de El Salvador. 
to, en Europa, por ejemplo, hay desinterés hacia algunas formas de expresiones hasta ayer clásicas de la religión, sobre todo, el catolicismo. Al mismo tiempo se nota un interés particular hacia prácticas o religiones esotéricas, por no decir exóticas. Proclamarse 'ateo' no es más hoy una moda y una exigencia como en los años sesenta. En aquella época, en particular en el mundo de la cultura, para sentirse una persona libre, capaz de ejercer autónomamente sus facultades, uno tenía que profesar el ateísmo y declarar haber deshecho los lazos con cada forma de Absolutismo.

Entonces, la indiferencia hacia la religión profetizada por algunos hasta ahora no tuvo lugar; más bien, notamos hoy que una alta calificación académica y el fundamentalismo religioso pueden darse la mano para la formación de terroristas, como se ha visto casos en varias partes del mundo en los últimos años. Podemos por tanto interrogarnos sobre las relaciones entre la religión y la universidad en la sociedad actual, entre fe y razón. El hecho de que la racionalidad científica parece no ser una condición suficiente contra el recurso a la violencia, que centros de formación intelectual puedan volverse el hogar de integristas religiosos, nos pone ante tres desafíos:

1. Redescubrir, calificar y tener claras las relaciones entre religiones y universidad.

2. Volver a precisar las identidades propias y las metas de ambas realidades.

3. Reinventar la vocación de la universidad.

\section{Religión y Universidad: una cuestión histórica y ontológica}

Para subrayar las relaciones congeniales entre Religión y Universidad no es necesario regresar hasta la antigüedad, cuando todavía no se había operado la separación entre lo profano y lo sagrado, y cuando el fenómeno religioso, con sus conceptos, sus estructuras sociales servían de base para la comprensión, la explicación del mundo y la educación. Las mismas universidades modernas nacieron en conexión con centros de cultos religiosos, a la sombra de iglesias o mezquitas.

Así, las primeras universidades modernas fundadas en Europa en los siglos XI-XV, la de Bolonia, de París, de Oxford o de Salamanca, que aún hoy constituyen los modelos de las universidades actuales, nacieron como el fruto de tres corrientes: la corriente de la tradición cristiana, la de tradición greco-romana y también aquella de la tradición oriental-árabe. En efecto, ya en los siglos IV y V, funcionaban, en el Oriente, las Escuelas de Edesa y Nisibis, constituidas por comunidades de maestros interesados por el estudio de las Sagradas Escrituras. Cuando, después de la expulsión del Imperio bizantino, los cristianos nestorianos se trasladan a Persia, allí fundaron la famosa Escuela de Medicina de Gondishapur. Más tarde (637-651), los musulmanes derrotan al Imperio persa, y trasladan a Bagdad dicha Escuela, que recibe el nombre de "Bayt al Hikma", la Casa de la Sabiduría: allá se traducían, sobre todo, las obras científicas de médicos y filósofos griegos.

Centros de estudios del mismo tipo, aparecerán en Europa, entre los siglos VIII y X, bajo el incentivo de los árabes, con la fundación de universidades como la de Córdoba en España (VIII), o la de Salerno en Italia (X). Sin embargo, es con la creación de la universidad de Bolonia (Italia), en 1088, que estamos de frente a un fenómeno nuevo: la fundación de centros de estudios que usan instrumentos intelectuales, la racionalidad elaborada por la cultura grecoromana para explicar, estructurar los datos de la fe cristiana, y por otra lado, proyectar la luz de esa sobre las primeras. Desde allí se difunde el fenómeno en todo el continente europeo, en donde las universidades se crearon por todas partes: la Universidad de Oxford (Inglaterra) en 1096; la Universidad de París (Francia) en 1150; la Universidad de Modena (Italia) en 1175; la 
Universidad de Cambridge (Inglaterra) alrededor de 1208; la Universidad de Palencia (España) en 1212; la Universidad de Salamanca (España) en 1218.

Etimológicamente, la palabra universidad (en latín universitas) se utilizaba para designar cualquier gremio corporativo, y las universidades europeas se conformarán como comunidades de maestros y estudiantes. Al final, terminó por designar el lugar en donde ese gremio particular ejercía sus actividades.

Es interesante subrayar que de un total de 44 universidades europeas creadas antes de 1400, por lo menos 31 contaron, en efecto, con un documento fundacional pontificio, lo que revela entre otras el carácter religioso si no eclesiástico de estas instituciones. Más aún al comienzo, las careras ofertadas eran exclusivamente teológicas o por lo menos eclesiásticas: los maestros y los estudiantes tuvieron que luchar para conseguir que se ofertaran otras carreras: en la Universidad de París, La Sorbona, por ejemplo, hicieron una huelga de tres años, desde 1229 hasta 1231.

En la actualidad, las universidades de Hunan (Changsha, China), fundada en 976 y la de Al-Azhar (El Cairo, Egipto), fundada en 988, figuran entre las más antiguas del mundo. Sin embargo, es el modelo de las universidades fundadas en Europa entre el XI y XV siglos que se difundió en el mundo entero, sobre todo a partir del siglo XVIII, a través del proceso de colonización. A este respecto, una nota histórica sobre las universidades en América Latina, ofrece una luz particular para el tema en estudio.

Las primeras universidades latinoamericanas de los tiempos modernos pertenecen a la época de la Colonia: fueron fundadas por la Corona Española, con excepción de las de Brasil. Entre las primeras figura la Universidad de Quito (1586) y el orden cronológico es más o menos el siguiente: Universidad de Santo Tomás de Aquino-República Dominicana (1538); Universidad Nacional Mayor de San Marcos Lima-Perú (1551); Universidad Nacional
Autónoma de México -UNAM- (1551); BogotáColombia (1573, 1580, 1621); San Luís-Ecuador (1594); Santo Tomas-Filipinas (1611); CórdobaArgentina (1613); Real Universidad de San Felipe (Chile) (1619, 1621, 1738); Chuquisaca-Bolivia (1624); Rosario-Colombia (1653); Universidad San Carlos de Guatemala (1676); HuamangaAyacucho-Perú (1677); Cusco-Perú (1692); Universidad de la Habana-Cuba (1721); Real y Pontificia Universidad de Caracas-Venezuela (1725); Guadalajara-México (1792).

Como sus modelos europeos, esas universidades, nacen a la sombra de las catedrales $y$, sobre todo, de conventos. En efecto, muy frecuentemente, las universidades creadas en América Latina por la Corona, se constituyeron como corporaciones semieclesiásticas administradas por jesuitas, dominicos, franciscanos, carmelitas, agustinos, con criterios de pertenencia, contenidos y metodología de enseñanza, estrictamente reglamentados y legadas a la fe cristiana y a su difusión.

De esa manera, es difícil, por no decir imposible, tener un conocimiento profundo del fenómeno universitario, sea en general o en particular, en América Latina y en Ecuador, sin referirse a ese pasado tan ligado a la religión. Más allá, hay un simple hecho: la religión, sus creencias y estructuras ofrecieron los sistemas de educación, los más antiguos de la humanidad. Así, los templos del antiguo Egipto, servían también de escuela de Escritura, de Ciencias, de Matemáticas y Arquitectura. Igualmente, en la India del pasado remoto, donde nació el budismo, la educación estaba básicamente en la mano de los sacerdotes. Y hoy, libros sagrados o religiosos, como la Biblia, el Talmud, la Tora y el Corán siguen siendo las fuentes básicas de educación, por lo menos moral o cívica de centenares de millones de seres humanos. De todas maneras, en la actualidad, en los países occidentales, el sistema de educación es tributaria de valores y tradiciones religiosas, sobre todo, judío-cristianas. En cambio, en los países 
mahometanos, sobre todo, en el medio Oriente y en una parte de Asia, la educación está inspirada por principios religiosos musulmanes o por otras religiones.

Entonces, todavía hoy, incluso en los Estados dichos laicos, donde se piensa que el proceso de laicización de la sociedad si cumplió plenamente, la educación está bajo la influencia de la religión y, en cambio, ésta tiene sus influjos sobre aquella. Queda establecer la razón profunda de ese hecho masivo, que en pocas palabras se puede expresar así: la religión dio luz a la universidad, o la universidad es hija de la religión. Y lo hizo por amor a lo más alto que hay en el ser humano: el espíritu (la mente) que la religión, a través de la educación, quiere ayudar a elevar hacia el cielo, hacia los ideales más nobles, hacia Dios. Por eso la separación entre la universidad y las religiones será solo aparente. Y aquí, como en todos los casos similares, estamos de frente a la dialéctica entre la tentación de la fusión y la necesitad de la alteridad.

\section{Religión y Universidad: el desafío de la identidad propia}

La profunda correlación congénita entre la religión y la educación condujo la una a negar o invadir el campo de la otra, provocando frecuentemente conflictos, rivalidades, o por lo menos discrepancias entre ambas, e igualmente entre las autoridades que las representan. Es allí que se pone la cuestión de la identidad propia de cada una.

Durante siglos, las autoridades científicas lucharon para conseguir la autonomía de la ciencia y de la universidad. Primero fue una lucha para obtener la extensión de las jurisdicciones locales y un margen de independencia que se cristalizó en la famosa "franquicia Universitaria", en función de la cual, aun bajo la autoridad del Estado, las universidades se presentan como un mini Estado dentro del

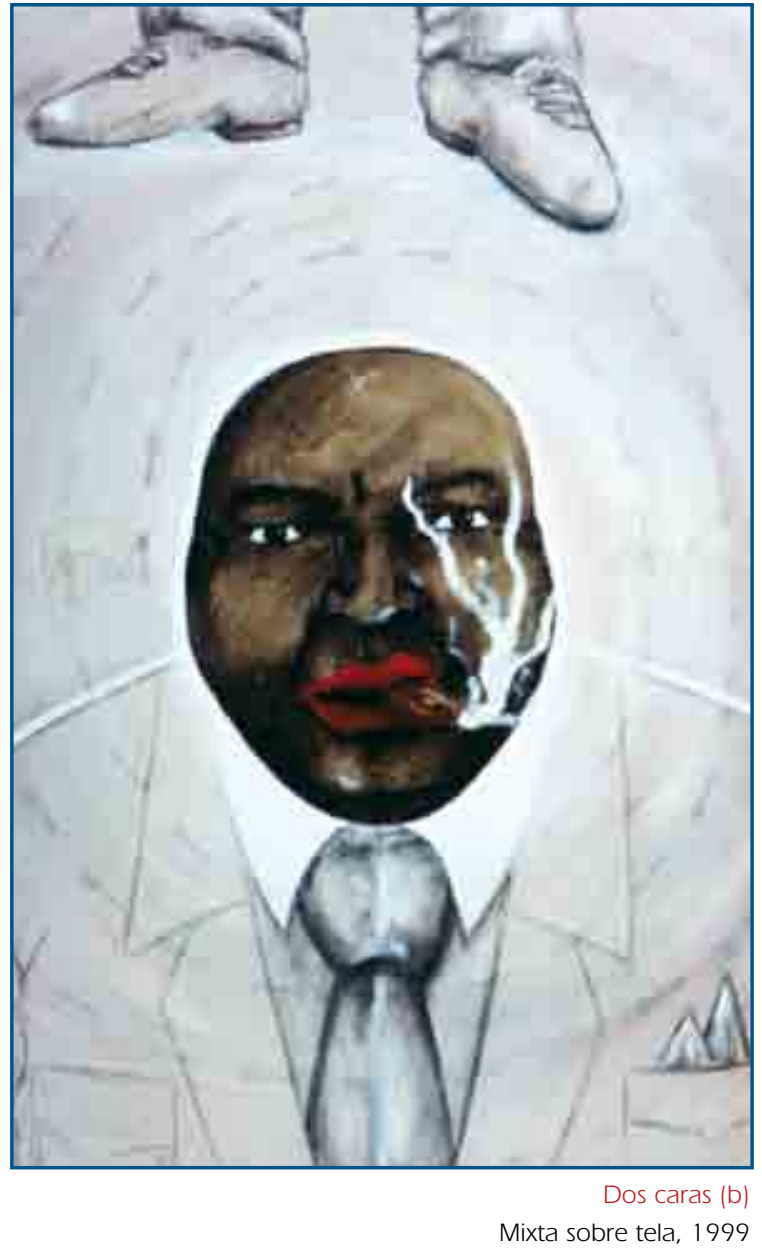

Estado. Y después, fue la lucha para obtener la autonomía, en cuanto se refiere a sus métodos de trabajo, de investigación; la facultad de usar el espíritu crítico-científico sin tener las intervenciones limitativas o interferencias negativas de poderes extraños. Uno de los casos más conocidos ha sido el de Galileo que tuvo, como se sabe, que retractarse de sus descubrimientos porque contradecía creencias religiosas. Hoy, aunque el contexto haya cambiado mucho, en el fondo, y más allá del mundo bajo la influencia de tradiciones cristianas, el tema sigue candente. $\mathrm{Al}$ respecto, ya en 1797, José María Blanco White, un español del siglo XIX, Diputado de Artes de la Junta de Gobierno de la Universidad Literaria de 
Sevilla, denunciaba la intrusión de los teólogos en todas las ramas del conocimiento humano:

La Astronomía tiene que pedir permiso a los inquisidores para ver con sus propios ojos... La Anatomía es juzgada sospechosa y vigilada de cerca siempre que toma el escalpelo, y la Medicina tuvo no poco que sufrir cuando se esforzaba en borrar del catálogo de pecados mortales el uso de la quina y la vacunación. No solo hay que creer lo que cree la Inquisición, sino que hay que dar fe implícita a las teorías y explicaciones de sus teólogos. ${ }^{1}$

A la luz de esos comentarios podemos imaginar todo lo que provocó a la ciencia y a la humanidad las invasiones poco felices de las religiones en el campo de la universidad y de la ciencia. Sin embargo, es conveniente por eso, rechazar completamente, si fuera posible, las religiones desde las esferas de la ciencia y de la universidad.

\section{Con las religiones, reinventar la vocación de la Universidad "Alma Mater"}

En todas las sociedades en las cuales se realizó ya la separación entre lo profano y lo sagrado o en las cuales el proceso está en curso, hay una lucha o una dualidad entre fe y razón, la ciencia y las creencias religiosas. Y la universidad es uno de los más importantes escenarios en donde esa lucha tiene lugar. Sin embargo, la rivalidad entre universidad y religión es la simple manifestación de la tentación del ser humano de cualquier época o cultura de declarase autor y dueño de todos los conocimientos; según el libro del Génesis, eso ha sido el primer pecado del ser humano, en el cual se originaron los demás: "Lo conoceréis todo y seréis como Dios" (Gen 3,5).

Es aquí que se tiene que subrayar lo siguiente: cierto, históricamente, la religión trató de imponer límites, algunas veces, indebidos a la ciencia, a la universidad. Esto ha sido parte de errores innegables o solamente de malas apreciaciones de situaciones de parte de autoridades religiosas, porque la ciencia en su templo que constituye la universidad necesita autonomía e independencia. Sin embargo, sería una verdadera catástrofe romper las relaciones entre la universidad, la ciencia, la educación y las religiones. La universidad, como la ciencia, tiene que preservar su autonomía, sus métodos, su identidad propia para conseguir su misión. Pero, la ciencia que quiere separarse completamente de la religión, se vuelve ciega, y puede, como la historia lo ha enseñado tantas veces, conducir al ser humano al abismo, como lo ocurrido durante la Segunda Guerra Mundial cuando la ciencia y la técnica, fueron usadas para deshumanizar al hombre y cometer atrocidades. Hoy que la ciencia pone en la mano de los seres humanos inmensos y a veces temibles poderes, ¿qué principios y quién los va a guiar para un uso adecuado de los mismos en pro del bien de la humanidad? Siempre, la ciencia y la técnica quedarán mudas en lo que se refiere al uso de los medios que proporcionan al ser humano. Al respecto, invariablemente la humanidad tuvo que dirigirse a la ética, a la reli-

1 En José M. Blanco Crespo, Cartas de España (Sevilla 1775, Liverpool 1841). José María Blanco White explica: “Gracias a la unión que hay entre nuestra Iglesia y nuestro Estado, los teólogos católicos casi han conseguido mantener la instrucción pública a su mismo nivel. Aun las ramas de la ciencia que parecen menos relacionadas con la religión, no pueden escapar de la férula de los teólogos, y el mismo espíritu que hizo a Galileo retractarse de rodillas de sus descubrimientos astronómicos todavía obliga a nuestros profesores a enseñar el sistema de Copérnico como una hipótesis. La verdad es que al lado de los teólogos católicos ninguna empresa de la inteligencia humana es inseparable de la religión. Desde el comienzo del cristianismo la doctrina cristiana ha estado siempre mezclada con las opiniones filosóficas de los que la enseñaban. Las mismas Sagradas Escrituras, a pesar de su inmenso valor para la formación moral, frecuentemente tocan de paso algunos temas que no guardan relación con su principal objetivo y tratan de la Naturaleza y de la sociedad civil de acuerdo con las ideas de un pueblo rudo en un periodo verdaderamente primitivo de su historia. De aquí la intrusión de los teólogos en todas las ramas del conocimiento humano, que todavía defienden los poderes civiles en gran parte de Europa, pero en ningún otro lugar tan fuertemente como en España". Ibíd. 
gión, a la conciencia de los hombres y mujeres. Allí está el sentido profundo de la famosa frase atribuida al pensador y escritor francés André Malraux: "El vigésimo secundo siglo será religioso o no será". Hoy la tecnología, en la mano del ser humano, es tan poderosa que sin principios morales $\mathrm{y}$ religiosos, sin una conciencia clara del bien y del mal, los hombres pueden llegar a destruirse y dañar profundamente el ambiente.

Igualmente, la religión que rechaza la ciencia y la razón de sus esferas, solo puede conducir al ser humano al oscurantismo, a prácticas irracionales, con las cuales pisando al prójimo, matando al semejante, cree dar gloria a la Divinidad. Dios siendo Puro Espíritu, la Inteligencia Suprema quien ordenó al mundo, no puede complacerse al ver a sus hijos en las tinieblas de la ignorancia. A este respecto, es muy bella esa observación de Pedro en su Primera Epístola: "Dios nos llamó de las tinieblas a su admirable luz" (cfr. 1 Ped 2, 9). $\mathrm{Y}$ es por eso que en el catolicismo es parte de la tradición más genuina, como lo recordó el Papa Juan Pablo II con su Encíclica Fides et Ratio (Fe y Razón), explicar y esclarecer los dados de la revelación con categorías de la razón humana: "la fe requiere que su objeto sea comprendido con la ayuda de la razón; la razón, en el culmen de su búsqueda, admite como necesario lo que la fe le presenta" (N. 42).

La universidad tiene que cumplir con su vocación de Alma Mater, de madre, con valores. Alma deriva del verbo latino alo/alere que signi- fica alimentar, amamantar, hacer crecer.

Las universidades fueron inventadas

para nutrir, como la religión el alma, el espíritu humano, individual y colectivamente. $\mathrm{Y}$ según el programa de la Institución libre de enseñanza a finales del siglo XIX, la universidad, además de preparar profesionales, académicos del más alto nivel, debe formar "pero sobre eso, y antes que todo eso, hombres, personas capaces de concebir un ideal, de gobernar con sustantividad su propia vida y de producirla mediante el armonioso consorcio de todas sus facultades". A este respecto, la religión con sus valores de generosidad, de solidaridad es un aliado y no un enemigo de la universidad. Y porque ambas incitan al ser humano a sobrepasarse, a buscar la perfección, quedarán de parientes y aliados.

Lastimosamente, en algunas partes del mundo, como la religión, la universidad comienza a ser desviada de sus nobles objetivos: corruptio optimi pessima, decían los romanos; la corrupción de lo que es noble en sus principios, puede ser tremenda. Si la universidad, y más allá de ella, los centros de educación, en vez de responder a la vocación de Alma Mater, en vez de nutrir el espíritu y el alma, los corrompe, entonces, la humanidad tendrá que preparase para enfrentar barbaridades que ni siquiera podemos imaginar.

La paz, la solidaridad, la armonía en el mundo de mañana dependen en grande parte, naturalmente de lo que pasa hoy en nuestras familias, pero también de lo que enseña y de lo que ocurre en los centros de formación. 